\title{
Remembering - Joan Edgecumbe (1942-2019)
}

\author{
By Dr Evelyn Hovenga with contributions from Judith Ronald, Lucy Westbrooke, \\ and Diane Skiba
}

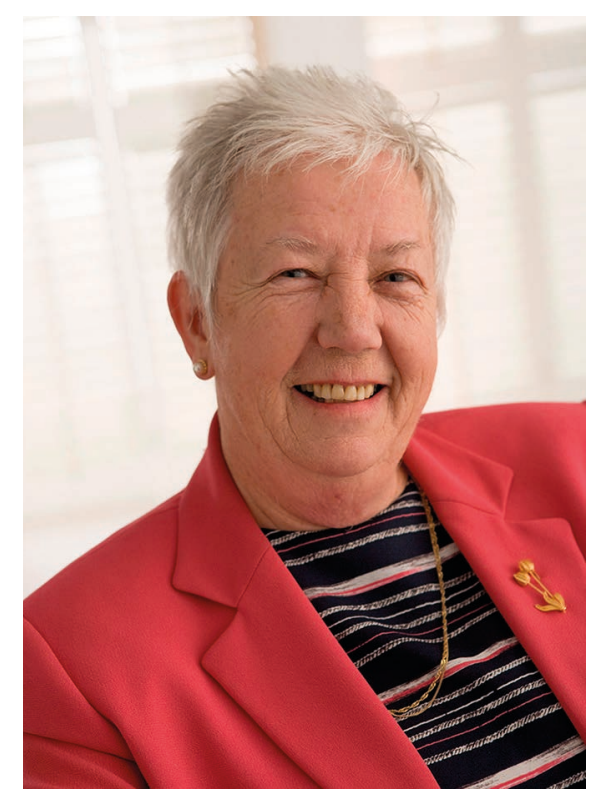

The sudden passing of Joan Edgecumbe on November $8^{\text {th }} 2019$ was a shock for all who loved and knew her. Joan had a strong commitment to the Health Informatics discipline. She dedicated herself to providing support for the national and international Health/ Medical Informatics communities for more than 30 years. Her vision was to transform for the better nursing, midwifery, and health care generally, and by educating the workforce accordingly. Her passion throughout was to provide educational opportunities to build the workforce's health informatics capacity. Joan became a member of IMIA's Senior Officers Club, was awarded honorary member of IMIA's Nursing Informatics (NI) Special Interest Group, honorary life member of Health Informatics Society of Australia (HISA), and of HISA NI.

Joan was born in Launceston, Tasmania (Australia). She began her professional work in the health industry as a pharmacist's assistant in 1959. She then undertook her nursing training at Launceston General Hospital, followed by midwifery training at the Women's Hospital in Melbourne completed in 1964, where she established her nursing career and worked till 1991. Joan managed the tertiary hospital's neonatal unit before being awarded a Florence Nightingale scholarship to undertake a Graduate Diploma in Nursing Administration. Joan then moved to administration where she conducted major hospital-wide special projects, focused on quality measurement, research, and informatics.

Joan first met Evelyn Hovenga during the early 1980s. At this time, Joan and her colleague Robyn Harvey had decided that nurses needed to have education in computing, so they both took a Diploma in Information Technology course in 1980 at the Footscray Technical and Further Education Institute (TAFE) in Melbourne (Australia). This was the start of Joan's career in Health Informatics. In 1985, Joan and Robyn called

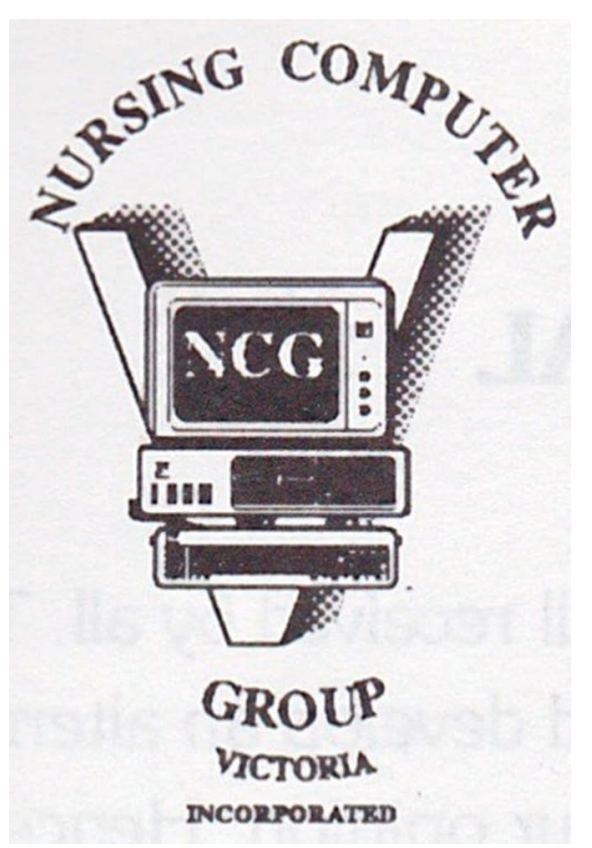

a meeting of nurses with a similar interest. More than 70 nurses and midwives turned up at St Georges Hospital Kew in Melbourne (Australia). Evelyn was one of those. This meeting of nurses and midwives resulted in the establishment of the Nursing Computer Group Victoria (NCGV). Evelyn nominated herself to be on this group's organising committee along with Joan.

Joan worked as Nursing Informatics consultant for primary care from 1991 to 1994. As noted by Judith Ronald, one of the first United States Representatives to the Nursing Informatics Working Group in IMIA, Joan was one of a small group of nurses who understood the impact that information technology would have on nursing and healthcare. She recognized the importance of having nurses actively involved in its development and was a strong advocate to make sure this happened. Judith would always remember Joan's wonderful smile and the twinkle in her eye as she worked with all members of the healthcare team to achieve her goals. Joan was committed to nursing, to patient care, and to the positive impact that healthcare informatics would have on them both.

The international link between the NCGV and IMIA was established by Evelyn. Joan managed the NCGV's memberships and finances. Joan established the Nursing computer group's logo and newsletter to advertise the many educational events that were subsequently organised. By 1986 this group had more than 200 members and $\$ 700$ in the bank when Evelyn suggested the group should consider putting in a submission to host the Fourth International Conference on nursing use of Computers and Information Science in Melbourne in 1991. Joan chaired this group till 1992 when the NCGV officially changed its name to Nursing Informatics Australia Inc. Joan again took over as the Chair of this newly established national group. 


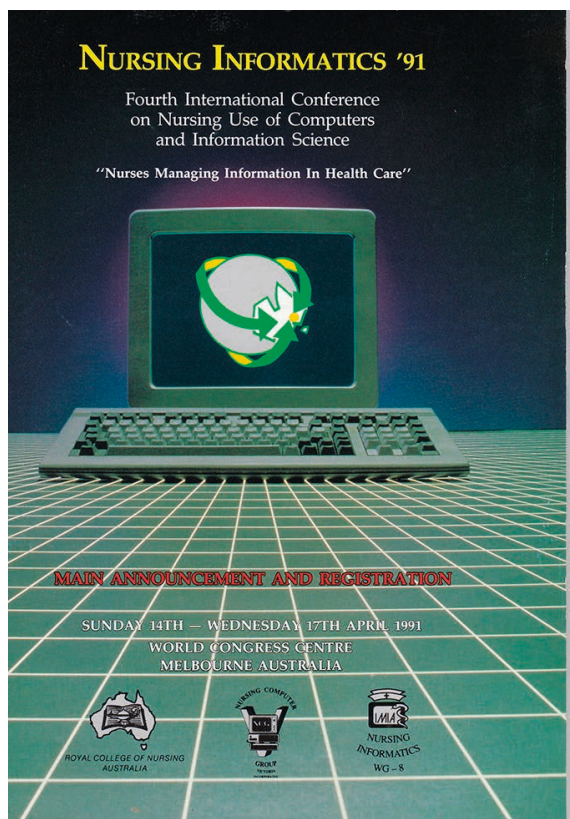

Together, Joan and Evelyn managed numerous challenges to make it happen, the most memorable of which was when they met with the State Bank Manager in the city to discuss the group's need for a $\$ 5,000$ unsecured loan to fund promotional activities. It was in the days when interest rates were double digits. The loan was approved and Joan established a rapport with the manager that enabled her to play the short term money market in a manner that contributed positively to the group's financial status. The conference was a great success, a big enough profit was made for Joan to initiate the establishment of a secretariat for the group using rented premises.

Diane J. Skiba, Chair of IMIA Nursing Informatics Special Interest Group (20162020), noted Joan's dedication and creative ideas to promote the Fourth International Conference on nursing use of Computer and Information Science. The Qantas airline agreed to be a sponsor, which included the delivery of a thousand brochures to advertise the conference in the United States. At that time, advertising was done via paper and not through the Internet. As the chair of the Nursing Informatics Special Interest Group in the United States, Diane was tasked with the distribution of these brochures to 800 plus members. Her first challenge was getting the 20 boxes of brochures out of the
Customs Office at the Denver airport. Joan and Diane laughed about the numerous car rides to and from the airport to Diane's office where her graduate students helped Diane to send out the brochures. Joan was a driving force and her perseverance spearheaded the incredible development of nursing informatics across the globe. She will be sadly missed by many of her American Colleagues.

Lucy Westbrooke, former Chair of IMIA Nursing Informatics Special Interest Group (2015-2016), noted that Joan played a very influential role in HISA and organised the Australian Health Informatics Conferences (HIC) from early days of Health Informatics in Australasia. NI1991 conference hosted in Melbourne (Australia) meant that some New Zealand nurses had the opportunity to attend their first international Nursing Informatics Conference. This lead to the formation of Nursing Informatics New Zealand (NINZ) in 1991. Throughout the 1990s, Joan as a representative of HISA collaborated with NINZ to bring international speakers to Australasia to be able to speak in both New Zealand and Australia. Many of NI colleagues in New Zealand knew Joan and had worked with her on collaborative efforts. Joan was a driving force and inspiration showing nurses were leaders in health informatics. She will be missed by her New Zealand colleagues.

The awareness of many other groups around the country who shared an interest in health informatics had enabled the establishment of a national network. The New South Wales (NSW) group's first annual conference was held in the Blue Mountains close to Sydney (Australia) in February 1992. Joan represented the Nursing Computer Group at this meeting and reported that at a round table meeting each member talked of the need for a "National Something", to enable all to work together towards improving Informatics in all health care settings. There was agreement on the need for a national magazine, a national voice, and a national platform on which Informatics could further support health care.

The Nursing group's executive accepted Joan's proposal for her newsletter to become the Informatics in Healthcare Australia Journal (IHAJ). The first issue of IHAJ was published in April 1992. Joan arranged for this IHAJ to be indexed in the Cumulative Index to Nursing and Applied Health Literature (CINAHL) and for all published

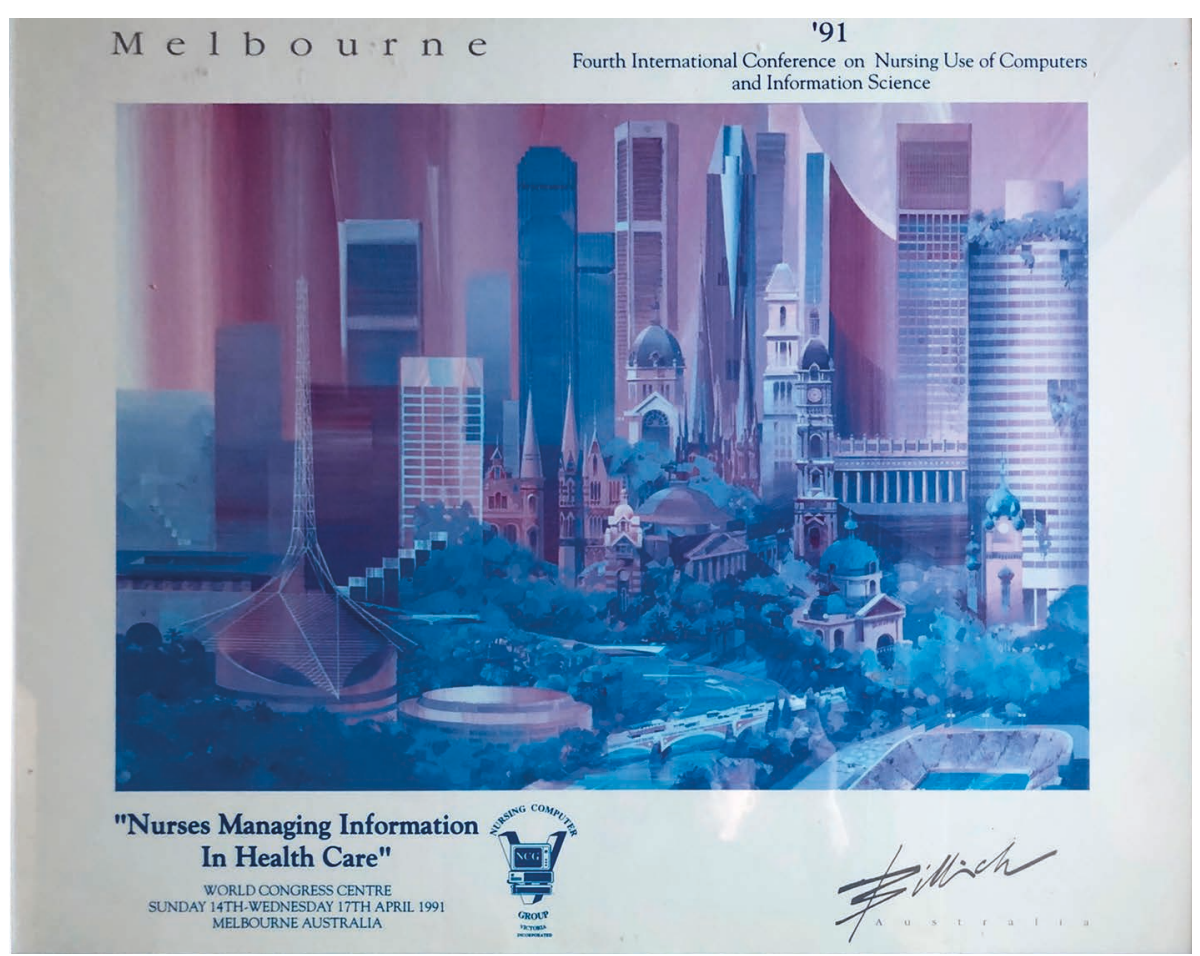


papers, including conference papers, to be made available via the Informit Health Collection managed by the Royal Melbourne Institute of Technology (RMIT). Eventually, Joan solicited Evelyn Hovenga to establish an online journal, which took over her journal's ISBN to become the electronic Journal of Health Informatics hosted by Central Queensland University.

Given Joan and Evelyn's experience with international conferences, it was decided to offer an annual national health informatics conference (HIC) in 1993. This initiative was supported financially by the NCGV. HIC' 93 facilitated the birth of HISA. The Nursing Group's secretariat then became the HISA secretariat. Joan took over the management of HISA's secretariat as its Executive Officer in 1995. In that capacity, she contributed to a number of Government funded initiatives, such as the Commonwealth Government's 1999 Health Online national strategy for information management and the use of online technologies within the Health sector and the Health Communication Network.

Joan and Evelyn continued to organise HIC for many years. Joan did all the logistics, liaisons with industry, and the financial management. Evelyn did the scientific program bits. Joan was instrumental in ensuring the continuing financial viability for HISA. She served as a HISA Board member for sever- al years. She often worked in a volunteer capacity putting in long hours. This was especially true in 1997 when HIC was held in conjunction with the Asia-Pacific Association of Medical Informatics (APAMI). There was an agreement to share profits made to give that organisation a head start and to host IMIA's Board meeting. Joan went without a salary for several months to ensure HISA stayed afloat at that time. Joan nurtured HISA's industry sponsors and was able to bring people together to work towards a common cause. She had a wonderful feeling for people, and was there to assist Enrico Coiera when he initiated the establishment of the Australasian College of Health Informatics (ACHI) in 2001.

Her persistence and total commitment to the promotion of the health informatics discipline and to HISA meant that she never gave up. Joan persevered with steely determination as conference manager despite some toxic working environment. In 2003, Joan lured Evelyn (reluctantly) back in the HISA camp for them to prepare the successful MedInfo 2007 bid.

Joan was able to recognise opportunities for innovation and to get support from HISA members to further develop new projects. One such example was a strategic proposal in 2003 to initiate an educational program centred on the International Computer
Drivers License (ICDL). Another was the continuing professional development (CPD) for the Australian health informatics sector/ workforce in 2006. Unfortunately, HISA did not approve either of these ideas.

In 2008, Joan retired from HISA but continued to work in the field of informatics. Evelyn and Joan established a private company, eHealth Education Proprietary Limited to provide this educational service. In 2010, the company agreed to acquire a Nationally recognised vocational training business. In order to acquire this business, Joan had to obtain a Certificate in Training and Assessment. Joan remained as the Director and Trainer of this company until her retirement in 2014.

Without Joan, HISA, HIC and all that followed would not have happened. In recognition of her outstanding contribution and unfailing support for HISA, an award was made available in her name following her retirement. Joan was welcoming to all who showed an interest in health or nursing informatics, she encouraged, supported, and assisted many individuals with their career development. Joan was a great leader who loved the health informatics community. She influenced many individuals who now have fond memories of having known Joan. Her friendship will never be forgotten, her legacy will live on. Farewell Joan, rest in peace. 